\title{
Barriers to Pharmacy-Based Syringe Purchase Among Injection Drug Users in Tijuana, Mexico: A Mixed Methods Study
}

\author{
Robin A. Pollini $\cdot$ Remedios Lozada $\cdot$ Manuel Gallardo • \\ Perth Rosen • Alicia Vera • Armando Macias • \\ Lawrence A. Palinkas · Steffanie A. Strathdee
}

Published online: 19 March 2010

(c) The Author(s) 2010. This article is published with open access at Springerlink.com

\begin{abstract}
Injection drug users (IDUs) may be denied purchase of sterile syringes even where purchase without a prescription is legal. This study examined barriers to overthe-counter (OTC) syringe purchase among IDUs in Tijuana, Mexico. A quantitative survey and subsequent focus groups were used to quantify barriers to purchase, identify their correlates and provide in-depth exploration of syringe purchase experiences. Of 627 IDUs, $81 \%$ purchased a syringe in the past 6 months and $16 \%$ were refused or overcharged. Factors independently associated with refusal/overcharging were homelessness, receptive syringe sharing, $>5$ uses per syringe, and number of lifetime abscesses. Few pharmacies sold syringes to IDUs, who adapted by limiting purchase attempts to pharmacies known to sell syringes consistently. Failed purchases occurred when drug withdrawal required purchase at unusual times or locations, often following release from jail. IDUs reported syringe sharing, syringe reuse, and searching through unsecured medical waste for syringes in response to failed purchase attempts. Interventions to expand OTC syringe sales to IDUs, particularly near detention facilities, will facilitate safer injection practices.
\end{abstract}

R. A. Pollini $(\bowtie) \cdot$ P. Rosen $\cdot$ A. Vera

L. A. Palinkas $\cdot$ S. A. Strathdee

Division of Global Public Health, Department of Medicine,

School of Medicine, University of California San Diego,

9500 Gilman Drive, Mailcode 0507, La Jolla, CA 92093, USA

e-mail: rpollini@ucsd.edu

R. Lozada $\cdot$ M. Gallardo $\cdot$ A. Macias

Patronado Pro-COMUSIDA, Tijuana, Mexico

L. A. Palinkas

Department of Social Policy and Health, School of Social Work,

University of Southern California, Los Angeles, CA, USA
Keywords Injection drug use - Pharmacies . Syringe access $\cdot$ Syringe sharing $\cdot$ Mexico

\section{Introduction}

Legal barriers that restrict pharmacy-based syringe sales constitute a structural barrier to HIV prevention [1]. In the United States, where prescription laws and regulations vary by state, research has shown that eliminating the need for a prescription is associated with increased syringe access and decreased sharing among injection drug users (IDUs). For example, IDUs in Connecticut were more likely to report pharmacy purchase of syringes (78 vs. 19\%) and less likely to report syringe sharing (31 vs. 52\%) following repeal of syringe prescription laws in 1992 [2]. In Minnesota, IDUs were almost three times more likely to purchase syringes at a pharmacy and 33\% less likely to report syringe sharing after the state enacted a law allowing non-prescription pharmacy sales of syringes [3]. Most recently, a New York study [4] showed that a newly established Expanded Syringe Access Demonstration Project was associated with a significant increase in the proportion of IDUs who obtained syringes from pharmacies, and that these IDUs were significantly less likely to report receptive syringe sharing.

Even in settings where syringes can be purchased without a prescription, IDUs face barriers to syringe purchase. Pharmacists and pharmacy staff may still be unwilling-for a variety of reasons - to sell syringes to persons they suspect of injection drug use. "Mystery shopper" studies, in which research staff posing as IDUs attempt to purchase syringes at pharmacies, have documented refusal rates of $31-59 \%$ in areas where overthe-counter (OTC) syringe purchase is legal [5-11]. Documented reasons for refusal include confusion regarding 
prevailing laws and regulations; pharmacists' attitudes regarding drug use and drug users; and commercial and safety considerations, including worries about theft, security, and increased drug use and discarded syringes near the pharmacy [12-20]. These studies establish a need for interventions that go beyond the "laws on the books" to address how policies are implemented "on the street," thus creating an environment that facilitates safer injection behaviors [21, 22].

OTC syringe sales are legal in Mexico. Tijuana, a city of approximately 1.4 million people located in Mexico's northwestern corner just across the border from San Diego, California, is home to $\sim 1,500$ pharmacies, which historically have thrived on business from Americans seeking to purchase relatively inexpensive pharmaceuticals. The ubiquity of these pharmacies makes them a convenient source of sterile syringes, which are much needed by local IDUs. Baja California, the state in which Tijuana is located, has the second highest cumulative AIDS incidence in Mexico [23]. Tijuana is situated on a major drug trafficking route that brings heroin, methamphetamine and other illicit drugs to the United States, and is increasingly becoming a domestic market for illicit drugs. Approximately 10,000 IDUs live in Tijuana and HIV prevalence is $4 \%$ among male IDUs, $10 \%$ among female IDUs, and $12 \%$ among female IDUs who also engage in sex work [24-26]. Although HIV prevalence remains somewhat low among Tijuana's IDUs syringe sharing is common, with 59\% reporting receptive syringe sharing in the past 6 months [27]. Hepatitis C prevalence in this population is 96\% [28].

Prior qualitative research ("El Cuete Phase I") by our group showed that despite the OTC status of syringes in Tijuana, some IDUs were refused or overcharged when they attempted to purchase syringes [29]. We undertook the current study to: (1) quantify the frequency of refusals and overcharges reported by IDUs at pharmacies in Tijuana; (2) triangulate these findings with the El Cuete Phase I qualitative findings; (3) identify factors associated with experiencing barriers to pharmacy purchase; and (4) provide a detailed understanding of these correlates within the context of IDUs' experiences.

\section{Methods}

\section{Study Design}

This study employed a sequential mixed methods design in which a cross-sectional quantitative study was conducted after a small qualitative study to validate the findings of the latter through convergence or triangulation, and in which the quantitative study was followed by another qualitative study to provide a contextual explanation of the quantitative results [30, 31]. Both studies were approved by the Ethics Board of the Tijuana General Hospital and the Human Research Protections Program of the University of California, San Diego. All study participants provided voluntary informed consent.

\section{Quantitative Data Collection}

The quantitative study was nested within a longitudinal study of behavioral and contextual factors for HIV, syphilis and TB infection among IDUs in Tijuana, Mexico ("El Cuete Phase III"). Eligible IDUs were $\geq 18$ years old, able to speak Spanish or English, and reported injecting illicit drugs in the last month. IDU status was confirmed by examination of injection stigmata. Overall, 1,056 IDUs were recruited between April 2006 and April 2007 using respondent driven sampling (RDS) [32] as previously described [27]. Briefly, a diverse group of "seeds" (heterogeneous by age, gender, and neighborhood) was selected and given uniquely coded coupons to refer their peers to the study. Waves of recruitment continued as subjects returning with coupons were given coupons to recruit members of their social networks. Recruitment and interviews were conducted by indigenous outreach workers through the use of a modified recreational vehicle and a storefront office.

At baseline and every 6 months thereafter, El Cuete III study participants completed an interviewer-administered survey that included questions on demographics; drug use and sexual behaviors; geographic locations of residence and drug use; syringe acquisition and use; injection-related morbidities (e.g., abscess, overdose); and interactions with police, which have previously been associated with syringe acquisition and injection behaviors among IDUs in Tijuana $[33,34]$. The "Determine" rapid HIV antibody test was used to detect the presence of HIV antibodies (Abbott Pharmaceuticals, Boston, MA). Reactive samples were confirmed using an HIV-1 enzyme immunoassay and immunofluorescence assay. At the second study visit, conducted during the period October 2006-January 2008, we added specific questions regarding recent attempts to purchase syringes at a pharmacy and the outcome of those attempts. For the purposes of analysis, IDUs who reported being overcharged and/or refused syringe purchase at a pharmacy in the past 6 months were categorized as having experienced barriers to pharmacy-based purchase.

\section{Qualitative Data Collection}

Between October 2008 and March 2009, we recruited a subset of 47 IDUs from El Cuete III to participate in focus groups designed to provide detailed descriptions of IDUs' experiences related to pharmacy syringe purchase. Five 
focus groups composed of exclusively male participants and two composed of female participants were held at the study's storefront office and led by a Mexican psychologist with experience in focus group facilitation. Male focus group participants were recruited based on their primary geographic area of drug use; specifically, we identified three high intensity drug use neighborhoods based on geographic information collected in the parent study and each focus group consisted of residents from a single one of these three neighborhoods to optimize the likelihood of shared pharmacy experiences. As only $14 \%$ of participants in the parent study were female, female focus group participants were purposefully recruited by study outreach personnel as they tracked participants for regularly scheduled El Cuete III follow-up visits.

Focus groups were conducted using a semi-structured interview guide that was developed based on earlier indepth qualitative interviews with IDUs in Tijuana, [29] results from the Phase III cross-sectional quantitative study, and a pilot focus group. Discussion topics focused on how IDUs chose the pharmacies for syringe purchase, detailed accounts of experiences in attempting to purchase syringes, descriptions of interactions with pharmacy staff, and specific barriers to pharmacy syringe purchase. Participants were also probed to describe the impact of these barriers on their injection practices. Each focus group lasted approximately $1 \mathrm{~h}$ and participants were reimbursed $\$ 20$ for their time.

\section{Data Analysis}

Quantitative data were analyzed by comparing the characteristics of IDUs who experienced barriers to pharmacy syringe purchase to those who did not, using Wilcoxon rank-sum tests for continuous variables and Pearson's chisquare test for categorical variables. Variables significant at $<0.20$ were manually entered into a multiple logistic regression model to identify factors independently associated with experiencing barriers to syringe purchase at a significance level $<0.05$. The analyses were performed using Stata statistical software [35]. The RDS recruitment method requires additional analyses to ensure that results from the multiple logistic regression model are both generalizable and valid [32]. The RDS Analysis Tool [36] was used to assess potential bias introduced by the non-random selection of seeds and a random effects logistic regression model using WinBUGS [37] was used to identify effects that might arise from correlation between recruiters and recruitees, as previously described [27]. Since results of the RDS-adjusted and unadjusted models yielded similar estimates, we present the unadjusted model herein.

Focus groups were digitally recorded, transcribed, translated from Spanish to English by a certified translator, and reviewed as they became available. An iterative process was used whereby questions and clarifications arising from real-time focus group observation and transcript review were used to inform facilitation of subsequent focus groups. Transcripts were double-coded using a descriptive and thematic approach in accordance with the "Coding Consensus, Co-occurrence, and Comparison" method and rooted in grounded theory [38, 39]. An explanatory design was used to explain or build upon initial quantitative results [40]. In this instance, themes identified from focus group transcripts were used to understand why certain characteristics were associated with experiencing barriers to syringe purchase. For the purposes of this paper, specific text excerpts were selected from the coded qualitative transcripts to provide context for the quantitative findings.

\section{Results}

Overall, 649 IDUs were administered the Visit 2 survey instrument of whom $627(96.6 \%)$ responded to the questions on pharmacy syringe purchase. A majority $(82.1 \%)$ was male and median age was 38 years (interquartile range [IQR]: 33-44). Almost all IDUs (87.5\%) reported injecting daily during the past 6 months; $80.7 \%$ reported injecting heroin alone, $51.3 \%$ injected heroin and methamphetamine together, and $14.2 \%$ injected methamphetamine alone. Few reported injecting cocaine, either alone $(0.6 \%)$ or in combination with heroin $(6.1 \%)$ or methamphetamine $(1.3 \%)$. More than one-third $(39.7 \%)$ reported receptive syringe sharing in the past 6 months.

\section{Barriers to Pharmacy Syringe Purchase-Frequencies}

Most IDUs (80.7\%) in the quantitative study reported purchasing a syringe in a pharmacy in the past 6 months; overall, $71.6 \%$ cited pharmacies as their primary source of syringes. Only $16.0 \%$ experienced barriers to pharmacy syringe purchase, including being refused purchase $(7.0 \%)$, being overcharged $(1.9 \%)$ or both $(7.0 \%)$.

These findings are in direct contrast to the qualitative findings in El Cuete Phase I, in which many participants reported refusal or overcharging when attempting to purchase syringes at pharmacies in Tijuana [29]. These conflicting findings can be attributed at least in part to differences in the time frames covered by the interviews, i.e., El Cuete Phase I interview questions were not timespecific while the Phase III interview questions covered only experiences in the past 6 months. They may also be attributed in part to different data collection timeframes, i.e., El Cuete Phase I data was collected in 2004 while El Cuete Phase III qualitative data were collected between October 2006 and January 2008. However, another 
explanation emerged early on in the focus groups: that IDUs in Tijuana have partially adapted to the barriers erected by local pharmacies through a process of identifying one or more pharmacies over time that will sell to them consistently. Generally, these pharmacies were identified through word-of-mouth. When IDUs did purchase sterile syringes, they visited these pharmacies almost exclusively and, in doing so, substantially reduced the likelihood that they would be refused or overcharged:

Man 1: ...we usually buy at one pharmacy in particular where they never deny [syringes] to us...of five pharmacies, only one sells them to us and that's where we go. But as for the others, we know by logic that they will not sell them to us there...[so] we don't go there.

In general, purchase attempts at pharmacies other than those regularly patronized occurred only when IDUs found themselves experiencing withdrawal symptoms at a time when their usual pharmacy was far away or closed. Purchase attempts at these pharmacies were more likely to result in refusals or overcharging. Several IDUs noted that withdrawal symptoms experienced late at night were especially problematic and led them to attempt syringe purchase at other pharmacies:

Man 1: [M]any of us struggle to get better and, well, we have the addiction 24 hours a day and pharmacies are not open all 24 hours. The pharmacies where we buy, well, they close early, and many times in the middle of the night, well, we're kind of looking [for a clean syringe] and it can't be found.

Withdrawal was reportedly common after release from police detention. IDUs in Tijuana can be held for up to $36 \mathrm{~h}$ by police without being charged, and upon release are anxious to inject heroin to relieve the withdrawal symptoms experienced as a result of their detention. The local detention center is in the neighborhood Veinte de Noviembre ("La Veinte"), which is a substantial distance from the neighborhoods in which most IDUs live, use drugs and purchase syringes. Several IDUs discussed experiencing difficulties accessing sterile syringes after their release. Further complicating the situation is the fact that they were often released from custody late at night:

Man 2: [O]ne time I left La Veinte around three in the morning or four and as I was saying it's very rare for them to sell to you there... on that side of Veinte de Noviembre, they don't sell syringes to you...You have to send someone who uses, what's it called? Insulin...but they don't sell to you, it's not easy to get syringes, and much less at three thirty or almost four in the morning and so instead I came over here...close to the hospital there's a pharmacy that's open 24 hours and there they sold it to me for 45 pesos...normally it's about 5 pesos, 10 pesos.

\section{Barriers to Pharmacy Syringe Purchase-Correlates} and Contexts

Table 1 presents results from the univariate analysis comparing characteristics of IDUs who did and did not encounter barriers to syringe access over the past 6 months. IDUs who experienced barriers were more likely to be homeless; to be stimulant users; and to engage in risky injection behaviors, including syringe sharing and reuse. They were also significantly more likely to cite pharmacies as a source of new syringes (94.0 vs. $76.5 \%, \chi^{2}=15.715$, $P<.001$ ), although less likely to view sterile syringe acquisition as "very easy" (12.0 vs. $27.4 \%, \chi^{2}=10.637$, $P=.005$ ), and more likely to report recent arrest for syringe possession (20.0 vs. $\left.9.9 \%, \chi^{2}=8.490, P=.004\right)$.

Table 2 shows results of a multiple logistic regression model that identifies four variables independently associated with experiencing barriers to pharmacy syringe purchase: homelessness, receptive syringe sharing, higher number of uses per syringe, and lifetime number of abscesses.

\section{Homelessness}

IDUs who reported homelessness during the past 6 months were more than twice as likely to report being refused or overcharged than IDUs who were not homeless (adjusted odds ratio $(\mathrm{AOR})=2.24 ; 95 \% \mathrm{CI}: 1.29,3.89)$. In the focus groups, participants did not cite a direct association between homelessness and barriers to syringe purchase, but referred frequently to unkempt appearance-often a direct consequence of homelessness - as a perceived reason for being refused syringes. "Appearance" was variably described as being influenced by the type and cleanliness of their clothing, cleanliness of their person, the presence of body odor and so on, but was almost universally identified by IDUs as a barrier to sterile syringe purchase at local pharmacies. One participant recalled an experience where the pharmacy worker specifically cited his appearance as unacceptable:

Man 2: And once I ...went by a pharmacy that was there by the one in [the Zona Río neighborhood] and I go in and I say to him, 'excuse me would you sell me [a syringe]' and he just looks at me, it's a man and he tells me, 'Hey', he says, 'make this the last time that I sell to you like with you coming like that. Next time,' he tells me, 'I won't sell syringes to people like you who come like that and if you want me to sell you syringes you have to take a shower and change, you have to look nice.' 
Table 1 Factors associated with barriers to pharmacy syringe purchase $^{\mathrm{a}}$ among IDUs in Tijuana, Mexico
${ }^{a}$ Past 6 months

b Test statistic is $z$-score for Wilcoxon rank-sum test

\begin{tabular}{|c|c|c|c|}
\hline & \multicolumn{2}{|c|}{ Refused/overcharged } & \multirow[t]{2}{*}{$\chi^{2}(P)$} \\
\hline & Yes $\%(n=100)$ & No $\%(n=527)$ & \\
\hline \multicolumn{4}{|l|}{ Demographics } \\
\hline Male & 82.0 & 82.2 & $.002(.969)$ \\
\hline Median age $(\mathrm{IQR})^{\mathrm{b}}$ & $37(33-43)$ & $38(33-44)$ & $.397(.692)$ \\
\hline Homeless $^{\mathrm{a}}$ & 23.0 & 11.0 & $10.749(.001)$ \\
\hline \multicolumn{4}{|l|}{ Injection drug use ${ }^{a}$} \\
\hline Heroin alone & 70.0 & 82.7 & $8.691(.003)$ \\
\hline Methamphetamine alone & 13.0 & 14.4 & $.139(.709)$ \\
\hline Cocaine alone & 3.0 & 0.2 & $10.472(.001)$ \\
\hline Heroin and methamphetamine & 61.0 & 49.4 & $4.502(.034)$ \\
\hline Heroin and cocaine & 7.2 & 5.9 & $.268(.605)$ \\
\hline Methamphetamine and cocaine & 1.0 & 1.3 & $.072(.789)$ \\
\hline Injected daily & 92.0 & 86.7 & $2.188(.139)$ \\
\hline Receptive syringe sharing & 52.0 & 37.2 & $7.709(.005)$ \\
\hline Distributive syringe sharing & 53.0 & 39.5 & $6.333(.012)$ \\
\hline Average \# uses per syringe $>5$ & 54.0 & 38.5 & $8.327(.004)$ \\
\hline \multicolumn{4}{|l|}{ Syringe acquisition ${ }^{\mathrm{a}}$} \\
\hline \multicolumn{4}{|l|}{ Sources for new syringes } \\
\hline Pharmacy & 94.0 & 76.5 & $15.715(<.001)$ \\
\hline Syringe exchange program & 41.0 & 35.7 & $1.029(.311)$ \\
\hline Market & 23.0 & 25.1 & $.189(.663)$ \\
\hline \multicolumn{4}{|l|}{ Ease of clean syringe acquisition } \\
\hline Very easy & 12.0 & 27.4 & $10.637(.005)$ \\
\hline Easy & 87.0 & 71.7 & \\
\hline Difficult & 1.0 & 1.0 & \\
\hline \multicolumn{4}{|l|}{ Interactions with police ${ }^{\mathrm{a}}$} \\
\hline Arrest for possessing new syringe & 12.0 & 8.9 & $.936(.333)$ \\
\hline Arrest for possessing used syringe & 20.0 & 9.9 & $8.490(.004)$ \\
\hline Arrest for track marks & 18.0 & 16.1 & $.214(.643)$ \\
\hline Police caused rushed injection & 10.0 & 5.9 & $2.332(.127)$ \\
\hline \multicolumn{4}{|l|}{ Injection associated morbidities } \\
\hline HIV positive & 7.2 & 5.9 & $.239(.625)$ \\
\hline Abscess last 6 months & 20.0 & 20.5 & $.013(.911)$ \\
\hline Abscess ever & 48.0 & 45.5 & $.205(.651)$ \\
\hline Median \# abscesses (lifetime) ${ }^{\mathrm{b}}$ & $0(0-3)$ & $0(0-2)$ & $-1.297(.195)$ \\
\hline
\end{tabular}

Table 2 Factors independently associated with barriers to pharmacy syringe purchase ${ }^{a}$ among IDUs in Tijuana, Mexico

\footnotetext{
${ }^{\text {a }}$ Past 6 months
}

\begin{tabular}{|c|c|}
\hline & $\begin{array}{l}\text { Adjusted odds ratio } \\
\text { (95\% confidence interval) }\end{array}$ \\
\hline Homeless $^{\mathrm{a}}$ & $2.24(1.29,3.89)$ \\
\hline Receptive syringe sharing ${ }^{\text {a }}$ & $1.57(1.01,2.45)$ \\
\hline Average uses per syringe $>5^{\mathrm{a}}$ & $1.74(1.11,2.71)$ \\
\hline Number of abscesses (lifetime) & $1.02(1.00,1.03)$ \\
\hline
\end{tabular}

IDUs generally believed that pharmacists were troubled by their appearance because it negatively affected the "image" of the pharmacy and thus was bad for business.
However, some participants reported being told by pharmacists that (despite the legality of OTC syringe sales) they feared trouble with the police if they were even perceived 
to be selling syringes to IDUs and were therefore reluctant to have anyone whose appearance suggested drug use in their pharmacy.

\section{Receptive Syringe Sharing}

In the quantitative study, experiencing barriers to syringe purchase was independently associated with receptive syringe sharing $(\mathrm{AOR}=1.57 ; 95 \% \mathrm{CI}: 1.01,2.45)$. This finding is consistent with the results of the El Cuete Phase I interviews, which found that syringe sharing was a direct response to experiencing barriers to sterile syringe access. In the focus groups, participants reported that they commonly responded to pharmacy refusals and overcharging by purchasing or sharing syringes that had already been used - a practice that placed them at risk of acquiring HIV, hepatitis $\mathrm{C}$ and other blood borne infections. Sources of used syringes included friends or other users from whom syringes were borrowed, purchased or traded for a few drops of the drug:

Man 2: I think that many [pharmacists] think that by prohibiting the sale of syringes that they are going to stop the usage of drugs...but what they are doing is wrong, because of that we have a harder time finding syringes. We need to use drugs in order to feel well, since when we are in need of a fix we feel desperate enough that we don't care and borrow one from a friend, since it's a desperate feeling we just don't care...

Others reported using syringes they found in medical waste when they could not purchase sterile syringes:

Man 1: They didn't want to sell [a syringe] to me and I had to go out and look and look for one [and] I found one of those that have been thrown away.

Man 3: We have even come to the point of also looking like that in places where they're used and see who, where those people are, you know like the Red Cross and all those places or the hospital or you look over there in the trash...Many times the need for [a syringe] makes us go look for them at the clinics where they throw them away, with the [biohazard] containers... you just wash them with water.

Still others reported using syringes found in household trash. The focus groups also included discussions of a secondary market for syringes in Tijuana, where syringes gathered through searching medical waste, household trash and the streets were washed and then resold to fill the gap left by inadequate sterile syringe supply.

\section{Syringe Reuse and Abscesses}

Reusing syringes an average of $>5$ times was significantly associated with experiencing barriers to syringe purchase in the final quantitative model $(\mathrm{AOR}=1.74 ; 95 \% \mathrm{CI}$ : $1.11,2.71)$. Male focus group participants seemed to view syringe reuse as normative and linked the practice directly to limited access to sterile syringes, including inability to purchase syringes from pharmacies:

Man 1: All syringes are for a single use, supposedly, right. [But] I'll carry it up to a month, for as long as it works.

Man 2: For as long as it works, seriously.

Man 3: [Y]ou want to get one and it depends on where you are, you're out of the neighborhood and they won't sell to you; I mean, so then instead you just say I'm going to take mine because even though it's all messed up, well, they won't sell to you there.

Male participants also described methods for keeping reused syringes in use for extended periods of time, which included sharpening the tip with matches, as well as describing the direct effects of using a dull syringe on the injection process:

Man 6: Sometimes, well, the truth is, one syringe, well, it can last you up to two or three days. Honestly, by the time you get to use it, it either stops working or it sticks to you. I mean, the blood clots, and so then you have to buy another one...

Discussion in the female focus groups focused primarily on the difficulties posed as a result of syringe reuse, with women citing their comparatively "small veins" as presenting problems for injecting with reused syringes:

Woman 2: [I] struggle to get my veins, you know, I just really need a new one and not just one syringe a day, no, I have to buy up to four syringes a day...because of the small veins we have.

Difficulty injecting due to syringe reuse-itself a direct outcome of limited access to new syringes — can result in "skin popping" and other injection practices that increase the risk of abscess. Even after controlling for syringe reuse in our quantitative model, experiencing barriers to pharmacy syringe purchase was marginally associated with a higher number of lifetime abscesses $(\mathrm{AOR}=1.02 ; 95 \%$ CI: $1.00,1.03$ ). In general, while focus group participants spoke frequently about the fact that syringe sharing put them at risk of HIV infection, none made a direct connection between reusing syringes and abscess risk until probed by the facilitator during the last focus group: 
Facilitator: Do you damage your skin because you don't have a new syringe? Have you gotten abscesses? Woman 2: I have gotten abscesses. Look, I have, I have them all over my arms because many times I've struggled with the syringes even because it doesn't have a tip and I don't get the vein well and since I suffer from my veins.

At the conclusion of each focus group, the facilitator asked the participants how having better access to syringes at pharmacies would affect their lives. While most IDUs talked about how expanded pharmacy-based syringe access would help them to avoid syringe sharing and HIV infection, none cited reductions in reuse or abscesses as a potential benefit of expanded pharmacy syringe access.

\section{Discussion}

Our quantitative study found that a majority of IDUs in Tijuana used pharmacies as their primary source for new syringes and few reported being recently refused or overcharged. These quantitative findings suggest that sterile syringe access is not a problem in Tijuana; however, they obscure the process through which IDUs have adapted to what is in reality a very limited market for syringes. Our focus groups ascertained that IDUs identified pharmacies (or more frequently a single pharmacy) that would sell syringes to them consistently and relied on those pharmacies almost exclusively, substantially reducing the likelihood of refusal or overcharging. These findings complement findings from our previous qualitative work in Tijuana, which documented barriers to pharmacy-based syringe access but not the subsequent process of adaptation [29]. They also provide a case study in the value of using multiple methods in HIV prevention research, as the quantitative findings alone would have provided a highly distorted view of the role of Tijuana pharmacies in sterile syringe access.

Our qualitative study found that this adaptive approach to syringe purchase can be easily disturbed, particularly when withdrawal symptoms necessitate immediate injection. IDUs described situations in which periods of police detention or mismanaged dosing led them to urgently seek a syringe in a location (e.g., near a detention facility) or at a time of day (e.g., late at night) that deviated from their usual routine. Efforts to obtain a sterile syringe under these circumstances were often unsuccessful and led directly to syringe sharing or reuse. The period immediately following release from jail or prison has been identified previously as a high risk time for overdose [41-43]. Our findings suggest that, where syringe access is limited, the immediate postrelease period is also a high risk time for syringe sharing. Prioritizing interventions for pharmacies located near detention facilities could substantially reduce syringe sharing among IDUs. Expanding access to sterile syringes late at night, when a majority of pharmacies are closed, could have a similar effect and warrants interventions especially targeted towards 24 -h pharmacies.

Our examination of correlates and contexts found that homeless IDUs were more than twice as likely to report barriers to syringe purchase. Numerous studies have reported associations between homelessness and high risk injection behaviors [44-49]. Hypothesized causal pathways include the need for homeless IDUs to find a discreet place to inject (e.g., shooting gallery) to avoid police detection, the need to rush injections in public places, and characteristics of homeless IDUs' social networks that normalize syringe sharing. Our focus group findings suggest another hypothesis: homeless IDUs may have difficulty purchasing OTC syringes where their right to do so is not enforced. The unkempt appearance of these IDUs may make them more identifiable to pharmacy staff as drug users, or may be viewed as offensive or frightening to other customers and bad for business, thus increasing the likelihood of refusal. A recent qualitative study from the United Kingdom similarly documented stigmatization of IDUs based on housing status and appearance, finding that these IDUs are stigmatized by both pharmacists and other IDUs [50]. Any interventions designed to improve pharmacy-based access to sterile syringes in Tijuana will need to include measures for addressing stigmatization of these highly marginalized IDUs.

While homelessness increases the likelihood that IDUs will be refused or overcharged when attempting to purchase syringes, the other correlates we observed were more likely to occur as a result of encountering these barriers. Focus group participants made a direct connection between their inability to purchase sterile syringes and syringe sharing, which places them at risk of infection with HIV and other blood borne pathogens. The link between restrictive pharmacy sales and syringe sharing has been previously reported [2-4]. Our study adds to this growing literature on syringe access and injection risk and makes clear the need for interventions to improve adherence to OTC syringe purchase laws. Interventions elsewhere have accomplished this through pharmacist training, information dissemination, and community outreach [51] and might serve as models for future interventions in Tijuana.

Among the more disturbing findings from our study is that IDUs linked restrictive syringe sales practices in Tijuana with the use of syringes salvaged from medical waste and household trash. Use of these syringes puts IDUs at risk of both viral and bacterial infections. Medical waste disposal at Tijuana clinics and hospitals is governed by laws similar to those in the U.S. (e.g., the California Medical Waste Management Act of 1990 [52]). Mexican law [53] 
requires that health facilities dispose of sharps in a punctureproof container with a top that can be permanently sealed. These containers must be kept in a restricted area until they are picked up for transport to a permitted disposal facility. The fact that IDUs report salvaging syringes from clinic waste in Tijuana suggests that adherence to this law may need stricter enforcement. In contrast, there are no Mexican laws governing home-based disposal of syringes. Across the border in California, a law governing disposal of homegenerated sharps didn't become effective until January 1, 2008, when Senate Bill 1305 closed a loophole in the state's Medical Waste Management Act that exempted these sharps from regulation. Passing a similar law designed to promote safer disposal of home-generated sharps in Mexico could reduce the likelihood that IDUs will salvage used syringes from household trash.

Finally, we found that experiencing barriers to syringe purchase is associated with higher odds of syringe reuse and abscesses. While these consequences did not appear to be as high a priority for IDUs as syringe sharing, which they linked clearly with HIV infection, abscesses are a frequent and sometimes serious complication of injection among IDUs in Tijuana and elsewhere [54-56]. Expanding OTC syringe access would increase the likelihood of using a new syringe for every injection.

This study was limited by the fact that we only interviewed IDUs. Subsequent research needs to include interviews with pharmacists and pharmacy staff in Tijuana to fully understand the factors that influence syringe sales practices and design appropriate interventions. Our studies were also conducted over a period of approximately 5 years, which may obscure any substantial changes in OTC syringe sales practices over time.

In summary, we found that pharmacies play an important role in meeting the syringe needs of IDUs in Tijuana but that restrictive sales practices limit the ability of IDUs to access sterile syringes where, when and in the quantities needed and lead to syringe sharing and reuse. Pharmacytargeted interventions to expand OTC syringe sales in Tijuana, particularly near detention facilities, would increase safe injection behaviors and reduce the likelihood of injection-related infections.

Acknowledgments This study was funded by the National Institute on Drug Abuse (K01DA022923 and R01DA019829). The authors gratefully acknowledge the contributions of study participants and staff; Pro-COMUSIDA, PrevenCasa and UCSD for assistance with data collection; Centro para la Prevencion y el Control de VIH/SIDA (CENSIDA); and Instituto de Servicios de Salud de Estado de Baja California (ISESALUD).

Open Access This article is distributed under the terms of the Creative Commons Attribution Noncommercial License which permits any noncommercial use, distribution, and reproduction in any medium, provided the original author(s) and source are credited.

\section{References}

1. Taussig JA, Weinstein B, Burris S, Jones TS. Syringe laws and pharmacy regulations are structural constraints on HIV prevention in the US. AIDS. 2000;14(Suppl 1):S47-51.

2. Groseclose SL, Weinstein B, Jones TS, Valleroy LA, Fehrs LJ, Kassler W. Impact of increased legal access to needles and syringes on practices of injecting-drug users and police officersConnecticut, 1992-1993. J Acquir Immune Defic Syndr Hum Retrovirol. 1995;10(1):82-9.

3. Cotten-Oldenburg NU, Carr P, DeBoer JM, Collison EK, Novotny G. Impact of pharmacy-based syringe access on injection practices among injection drug users in Minnesota, 1998 to 1999. J Acquir Immune Defic Syndr. 2001;27(2):183-92.

4. Pouget ER, Deren S, Fuller CM, et al. Receptive syringe sharing among injection drug users in Harlem and the Bronx during the New York State Expanded Syringe Access Demonstration Program. J Acquir Immune Defic Syndr. 2005;39(4):471-7.

5. Compton WM III, Cottler LB, Decker SH, Mager D, Stringfellow R. Legal needle buying in St. Louis. Am J Public Health. 1992;82(4):595-6.

6. Compton WM, Horton JC, Cottler LB, et al. A multistate trial of pharmacy syringe purchase. J Urban Health. 2004;81(4):661-70.

7. Deibert RJ, Goldbaum G, Parker TR, et al. Increased access to unrestricted pharmacy sales of syringes in Seattle-King County, Washington: structural- and individual-level changes, 1996 versus 2003. Am J Public Health. 2006;96(8):1347-53.

8. Finkelstein R, Tiger R, Greenwald R, Mukherjee R. Pharmacy syringe sale practices during the first year of expanded syringe availability in New York City (2001-2002). J Am Pharm Assoc. 2002;42(6 Suppl 2):S83-7.

9. Koester SK, Bush TW, Lewis BA. Limited access to syringes for injection drug users in pharmacies in Denver, Colorado. J Am Pharm Assoc. 2002;42(6 Suppl 2):S88-91.

10. Blumenthal WJ, Springer KW, Jones TS, Sterk CE. Pharmacy student knowledge, attitudes, and beliefs about selling syringes to injection drug users. J Am Pharm Assoc. 2002;42(6 Suppl 2):S34-9.

11. Trubatch BN, Fisher DG, Cagle HH, Fenaughty AM, Johnson ME. Nonprescription pharmacy sales of needles and syringes. Am J Public Health. 2000;90(10):1639-40.

12. Farley TA, Niccolai LM, Billeter M, Kissinger PJ, Grace M. Attitudes and practices of pharmacy managers regarding needle sales to injection drug users. J Am Pharm Assoc. 1999;39(1): 23-6.

13. Glanz A, Byrne C, Jackson P. Role of community pharmacies in preventing AIDS among injecting drug misusers: findings from a survey in England and Wales. BMJ. 1989;299(6707):1076-9.

14. Lewis BA, Koester SK, Bush TW. Pharmacists' attitudes and concerns regarding syringe sales to injection drug users in Denver, Colorado. J Am Pharm Assoc. 2002;42(6 Suppl 2):S46-51.

15. Marks RW, Hanrahan M, Williams DH, Goldbaum G, Thiede H, Wood RW. Encouraging pharmacy sale and safe disposal of syringes in Seattle, Washington. J Am Pharm Assoc. 2002;42(6 Suppl 2):S26-7.

16. Singer M, Baer HA, Scott G, Horowitz S, Weinstein B. Pharmacy access to syringes among injecting drug users: follow-up findings from Hartford, Connecticut. Public Health Rep. 1998;113(Suppl 1): S81-9.

17. Taussig J, Junge B, Burris S, Jones TS, Sterk CE. Individual and structural influences in shaping pharmacists' decisions to sell syringes to injection drug users in Atlanta, Georgia. J Am Pharm Assoc. 2002;42(6 Suppl 2):S40-5.

18. Tsai R, Goh EH, Webeck P, Mullins J. Prevention of human immunodeficiency virus infection among intravenous drug users 
in New South Wales, Australia: the needles and syringes distribution programme through retail pharmacies. Asia Pac J Public Health. 1988;2(4):245-51.

19. Wolfe T, Amelunxen V, Torres D, Jenison S, Churchill J. Encouraging pharmacy sale of syringes to injection drug users in New Mexico. J Am Pharm Assoc. 2002;42(6 Suppl 2):S32-3.

20. Wright-De Aguero L, Weinstein B, Jones TS, Miles J. Impact of the change in Connecticut syringe prescription laws on pharmacy sales and pharmacy managers' practices. J Acquir Immune Defic Syndr Hum Retrovirol. 1998;18(Suppl 1):S102-10.

21. Burris S, Blankenship KM, Donoghoe M, et al. Addressing the 'risk environment' for injection drug users: the mysterious case of the missing cop. Milbank Q. 2004;82(1):125-56.

22. Rhodes T, Singer M, Bourgois P, Friedman SR, Strathdee SA. The social structural production of HIV risk among injection drug users. Soc Sci Med. 2005;61(5):1026-44.

23. Consejo Nacional para la Prevención y Control del VIH/SIDA. Casos de SIDA e incidencia acumulada, según entidad federativa. 2009 Mar 31. http://www.censida.salud.gob.mx/descargas/2009/ cifras/04_Incidencia.pdf. Accessed 23 Nov 2009.

24. Brouwer KC, Strathdee SA, Magis-Rodriguez C, et al. Estimated numbers of men and women infected with HIV/AIDS in Tijuana, Mexico. J Urban Health. 2006;83(2):299-307.

25. Strathdee SA, Lozada R, Ojeda VD, et al. Differential effects of migration and deportation on HIV infection among male and female injection drug users in Tijuana, Mexico. PLoS One. 2008;3(7):e2690.

26. Strathdee SA, Philbin MM, Semple SJ, et al. Correlates of injection drug use among female sex workers in two Mexico-U.S. border cities. Drug Alcohol Depend. 2008;92(1-3):132-40.

27. Strathdee SA, Lozada R, Pollini RA, et al. Individual, social, and environmental influences associated with HIV infection among injection drug users in Tijuana, Mexico. J Acquir Immune Defic Syndr. 2008;47(3):369-76.

28. White EF, Garfein RS, Brouwer KC, et al. Prevalence of hepatitis $\mathrm{C}$ virus and HIV infection among injection drug users in two Mexican cities bordering the US. Salud Publica Mex. 2007;49(3):165-72.

29. Strathdee SA, Fraga WD, Case P, et al. "Vivo para consumirla y la consume para vivir" ["I live to inject and inject to live"]: highrisk injection behaviors in Tijuana, Mexico. J Urban Health. 2005;82(3 Suppl 4):iv58-73.

30. Creswell JW, Plano Clark VL, Gutmann ML, Hanson WE. Advanced mixed methods research designs. In: Tashakkori A, Teddlie CB, editors. Handbook of mixed methods in social \& behavioral research. Thousand Oaks: Sage Publications Inc.; 2003. p. 209-40.

31. Ivankova NV, Creswell JW, Stick SL. Using mixed-methods sequential explanatory design: from theory to practice. Field Methods. 2006;18(1):3-20.

32. Heckathorn DD. Respondent-driven sampling: a new approach to the study of hidden populations. Soc Probl. 1997;44(2):174-99.

33. Miller CL, Firestone M, Ramos R, et al. Injecting drug users' experiences of policing practices in two Mexican-U.S. border cities: public health perspectives. Int J Drug Policy. 2008;19(4):324-31.

34. Pollini RA, Brouwer KC, Lozada RM, et al. Syringe possession arrests are associated with receptive syringe sharing in two Mexico-US border cities. Addiction. 2008;103(1):101-8.

35. StataCorp. Stata Statistical Software, Release 11. College Station: StataCorp LP; 2009.

36. Respondent Driven Sampling Analysis Tool. Version 5.6.0. New York: Cornell University; 2006.

37. Lunn DJ, Thomas A, Best N, Spiegelhalter D. WinBUGS-a Bayesian modeling framework: concepts, structures, and extensibility. Stat Comput. 2000;10:325-37.
38. Willms DG, Best AJ, Taylor DW, et al. A systematic approach for using qualitative methods in primary prevention research. Med Anthropol Q. 1992;4(4):391-409.

39. Glaser BG, Strauss AL. The discovery of grounded theory: strategies for qualitative research. New York: Aldine de Gruyter; 1967.

40. Creswell JW, Plano Clark VL. Designing and conducting mixed methods research. Thousand Oaks: Sage Publications, Inc.; 2006.

41. Binswanger IA, Stern MF, Deyo RA, et al. Release from prisona high risk of death for former inmates. $\mathrm{N}$ Engl $\mathrm{J}$ Med. 2007;356(2):157-65.

42. Bird SM, Hutchinson SJ. Male drugs-related deaths in the fortnight after release from prison: Scotland, 1996-99. Addiction. 2003;98(2):185-90.

43. Seaman SR, Brettle RP, Gore SM. Mortality from overdose among injecting drug users recently released from prison: database linkage study. BMJ. 1998;316(7129):426-8.

44. Aidala A, Cross JE, Stall R, Harre D, Sumartojo E. Housing status and HIV risk behaviors: implications for prevention and policy. AIDS Behav. 2005;9(3):251-65.

45. Corneil T, Kuyper L, Shoveller J, et al. Unstable housing, associated risk behavior, and increased risk for HIV infection among injection drug users. Health Place. 2006;12(1):79-85.

46. Des Jarlais DC, Braine N, Friedmann P. Unstable housing as a factor for increased injection risk behavior at US syringe exchange programs. AIDS Behav. 2007;11(6 Suppl):S78-84.

47. German D, Davey MA, Latkin CA. Residential transience and HIV risk behaviors among injection drug users. AIDS Behav. 2007;11(6 Suppl):S21-30.

48. Lum PJ, Sears C, Guydish J. Injection risk behavior among women syringe exchangers in San Francisco. Subst Use Misuse. 2005;40(11):1681-96.

49. Philbin M, Pollini RA, Ramos R, et al. Shooting gallery attendance among IDUs in Tijuana and Ciudad Juarez, Mexico: correlates, prevention opportunities, and the role of the environment. AIDS Behav. 2008;12(4):552-60.

50. Simmonds L, Coomber R. Injecting drug users: a stigmatised and stigmatising population. Int J Drug Policy. 2009;20(2):121-30.

51. Fuller CM, Galea S, Caceres W, Blaney S, Sisco S, Vlahov D. Multilevel community-based intervention to increase access to sterile syringes among injection drug users through pharmacy sales in New York City. Am J Public Health. 2007;97(1):117-24.

52. California Department of Public Health. Medical Waste Management Act, California Health and Safety Code, Sections 117600118360. Jan 2007. http://www.cdph.ca.gov/certlic/medicalwaste/ Documents/MedicalWaste/MedicalWasteManagementAct.pdf. Accessed 11 Feb 2010.

53. Secretaria de Salúd. NORMA Oficial Mexicana NOM-087ECOL-SSA1-2002, Protección ambiental - Salud ambiental Residuos peligrosos biológico-infecciosos - Clasificación y especifcaciones de manejo. Feb 2003. http://www.salud.gob.mx/ unidades/cdi/nom/087ecolssa.html. Accessed 11 Feb 2010.

54. Binswanger IA, Kral AH, Bluthenthal RN, Rybold DJ, Edlin BR. High prevalence of abscesses and cellulitis among communityrecruited injection drug users in San Francisco. Clin Infect Dis. 2000;30(3):579-81.

55. Lloyd-Smith E, Kerr T, Hogg RS, Li K, Montaner JSG, Wood E. Prevalence and correlates of abscesses among a cohort of injection drug users. Harm Reduct J. 2005;2:24.

56. Pollini RA, Gallardo M, Hasan S, et al. High prevalence of abscesses and self-treatment among injection drug users in Tijuana, Mexico. Int J Infect Dis (in press). 